\title{
The use of Ki-67 labeling index to grade pulmonary well- differentiated neuroendocrine neoplasms: current best evidence
}

\author{
Alberto M. Marchevsky ${ }^{1} \cdot$ Andrew Hendifar ${ }^{2} \cdot$ Ann E. Walts ${ }^{1}$ \\ Received: 7 February 2018 / Revised: 4 April 2018 / Accepted: 8 April 2018 / Published online: 25 May 2018 \\ (c) United States \& Canadian Academy of Pathology 2018
}

\begin{abstract}
Although Ki-67 labeling index (Ki-67\%) is not a diagnostic or grading criterion in the World Health Organization classification of pulmonary carcinoid tumor, oncologists often request this test. A survey was administered at a North American Society for Neuroendocrine Tumors meeting to understand how Ki-67\% is used in oncologic practices. A systematic literature review was performed to gather best evidence regarding the use of Ki-67\%. Consecutive pulmonary carcinoids were stratified into pulmonary typical carcinoids with Ki-67\% $<5 \%$ (group A, $n=187$ ), typical carcinoids with $\mathrm{Ki}-67 \% \geq 5 \%$ (group B, $n=38$ ) and atypical carcinoids irrespective of Ki-67\% (group C, $n=31$ ). Overall survival, progression-free survival, recurrence proportions and time to recurrence were compared, by group, using the log-rank test, chi-square statistics and ANOVA, respectively. Our survey confirmed that Ki-67\% is frequently used by specialists caring for these patients. Ki-67\% of 1-7\% significantly correlated with overall survival in the literature but we found no information about Ki-67\% cut-off values that would accurately distinguish pulmonary typical from atypical carcinoids or estimate the prognosis of patients stratified by World Health Organization diagnosis and Ki-67\% cut-off. Overall survival was significantly different in our 3 patient groups $(p<0.001)$, with survival probabilities decreasing from groups A to C. Progression-free survival was significantly longer in group A than B $(p<0.007)$. Our results support the concept that by combining World Health Organization diagnosis and Ki-67\%, pulmonary carcinoids can be stratified into 3 grades: G1 (typical carcinoids with Ki-67\% <5), G2 (typical carcinoids with Ki-67\% 25\%) and G3 (atypical carcinoids) with different prognoses.
\end{abstract}

\section{Introduction}

Siegfried Oberndorfer described small intestinal lesions resembling "little carcinomas" as "carcinoids" in 1907 [1, 2]. Histologically similar tumors were subsequently described as primary neuroendocrine neoplasms originating in the lungs, pancreas, urothelial tract, genitourinary tracts and other sites [3-8]. In 2009 and 2015, the World Health Organization classified pulmonary neuroendocrine neoplasms into typical carcinoids, atypical carcinoids and high-grade neuroendocrine carcinomas

Alberto M. Marchevsky

Alberto.Marchevsky@cshs.org

1 Department of Pathology and Laboratory Medicine, Cedars-Sinai Medical Center, Los Angeles, CA, USA

2 Samuel Oschin Comprehensive Cancer Center, Cedars-Sinai Medical Center, Los Angeles, CA, USA including large-cell neuroendocrine carcinoma or smallcell carcinoma and their variants [9]. Pulmonary neuroendocrine neoplasms are distinguished from each other using histopathologic features such as mitotic activity, presence or absence of necrosis and cytologic features proposed by Travis et al. [10] in 1991. Current World Health Organization diagnostic criteria do not include the use of the Ki-67 labeling index (Ki-67\%) [9-16]. In contrast, in 2010 and 2017 using different histopathologic criteria than those used in the lung and various cut-off values for $\mathrm{Ki}-67 \%$, the World Health Organization proposed a classification scheme for neuroendocrine neoplasms arising in the gastroenteric tract and pancreas, designating these gastroenteric pancreatic tumors as grades 1-3 well-differentiated neuroendocrine tumor and grade 3 poorly differentiated neuroendocrine carcinoma [17-20].

Use of the term "carcinoid" for pulmonary neuroendocrine neoplasms has been somewhat problematic. In the past, these tumors were grouped with mucoepidermoid and 
adenoid cystic carcinomas into a general category of "bronchial adenomas", implying that pulmonary carcinoids were benign neoplasms $[16,21]$. We have noted that some physicians still adhere to this misconception. More recently, oncologists question why some neuroendocrine neoplasms are diagnosed by pathologists as carcinoids and others as grade 1-3 well-differentiated neuroendocrine tumors [8, 19]. This variability in pathologic nomenclature and diagnostic criteria can create problems, particularly during the management of metastatic lesions to the liver and other organs. In daily practice and at tumor boards, when oncologists at our institution ask for the grade of a metastatic neuroendocrine neoplasm, pathologists struggle trying to decide whether the lesion should be classified using the lung nomenclature (typical carcinoid, atypical carcinoid or high-grade neuroendocrine carcinoma) or the World Health Organization schema for gastrointestinal and pancreatic neoplasms (grade 1-3 well-differentiated neuroendocrine tumors or grade 3 poorly differentiated neuroendocrine carcinoma). Clinicians also expect $\mathrm{Ki}-67 \%$ to be included in all of our neuroendocrine neoplasms pathology reports, although there are currently no consensus or evidence guidelines on how to interpret the results of this test in pulmonary carcinoid tumor cases. The routine evaluation of Ki-67\% in our pulmonary carcinoid tumor cases has identified a subset of well-differentiated neuroendocrine neoplasms that should be classified as typical carcinoids by World Health Organization criteria but exhibit higher than expected $\mathrm{Ki}-67 \%$. It is uncertain whether the diagnosis of these tumors should be changed to atypical carcinoid based on the Ki-67 labeling index data and whether patients with these neoplasms have a different prognosis than those with typical carcinoid tumors exhibiting lower Ki-67 labeling indices. Although Ki-67\% provides significant prognostic information for patients with well-differentiated pulmonary neuroendocrine neoplasms, there is some overlap in the values found in tumors classified as typical carcinoid and atypical carcinoid by World Health Organization criteria [3, 4, 17, 22-28].

The current study was performed to learn whether these clinical issues are unique to our institution or are shared by colleagues at other hospitals, and to collect best evidence from the literature and our own experience regarding the current use and interpretation of $\mathrm{Ki}-67 \%$ in the diagnosis and management of pulmonary carcinoid tumors in general and particularly in cases that are diagnosed as typical carcinoids by World Health Organization criteria but exhibit higher than usual $\mathrm{Ki}-67 \%$. The study was also designed to evaluate whether there is sufficient evidence to propose a grading system for pulmonary carcinoid tumors that resembles the grading system currently used for gastrointestinal and pancreatic well-differentiated neuroendocrine tumors.
Table 1 Survey designed to learn how oncologists specializing in the treatment of neuroendocrine neoplasm (NEN) patients use diagnostic terminology and $\mathrm{Ki}-67$ labeling index values in practice

1- Do you find the information provided by the Ki-67 proliferative index useful for selecting therapy in patients with pulmonary carcinoid tumors?

2- Do you find the information provided by the Ki-67 proliferative index useful for informing patients with pulmonary carcinoid tumors about their prognosis?

3 - If you use the information provided by the $\mathrm{Ki}-67$ proliferative index in your decision process, what value do you consider significant as a "poor prognostic" feature that may require more aggressive therapy in patients with pulmonary carcinoid tumors?

A- $2 \%$

B- $5 \%$

C- $10 \%$

D- Higher than $10 \%$

E- Don't know would ask pathologist

4- Pathologists use different criteria and terminology for the diagnosis of low-grade/intermediate grade neuroendocrine tumors arising in different locations. Does this variability create problems in your practice?

5- Is it important for the selection of therapy in patients with a metastatic neuroendocrine tumor of "unknown origin" to determine the site of origin?

\section{Materials and methods}

The survey shown in Table 1 was emailed to 189 physicians who participated in the October 2017 North American Neuroendocrine Tumor Society annual meeting to assess whether oncologists at other institutions also encounter problems during the evaluation of neuroendocrine neoplasm patients because of the diagnostic issues described above. The survey included three questions designed to evaluate how oncologists specializing in the treatment of patients with pulmonary carcinoid tumors use $\mathrm{Ki}-67 \%$ in managing their patients, one question designed to learn whether the current use of different terminology in the diagnosis of neuroendocrine neoplasms arising in different organs creates problems in their practice, and one question designed to learn whether they consider the identification of the site of origin important for management of a metastatic neuroendocrine neoplasm.

Data from the literature and our own experience were evaluated using a previously described systematic evidencebased approach that includes the following: (1) formulation of specific questions that address clinico-pathologic problems, (2) systematic literature review to query for published best evidence that would answer the questions, (3) review of personal experience and (4) integration of these data to provide responses to the specific questions [2, 29]. Table 2 shows the questions used to query the literature and our own experience. A systematic literature review was 
Table 2 Questions designed to query the literature and our own experience about the potential use of $\mathrm{Ki}-67 \%$ labeling index as a diagnostic feature for the classification of pulmonary carcinoid tumors

1-How many pulmonary typical and atypical carcinoid cases were included in the study?

2-Which methods were used to measure the Ki-67 labeling index? Random selection of cells or hotspot? Manual or automated quantitation?

3-Did the study report a cut-off value for Ki-67 labeling index that is significantly associated with prognosis? What prognostic metric(s) was (were) evaluated?

4-Did the study evaluate the prognosis of patients with tumors that have Ki-67 labeling indices below and above the cut-off value reported to be significantly associated with prognosis?

performed using the PubMed search engine of the National Library of Medicine and the search words Ki-67, carcinoid and lung neoplasms. The main purpose of the systematic review was to query the literature for Ki-67\% cut-offs that would provide significantly worse prognosis for patients with pulmonary carcinoid tumors. Exclusion criteria for the systematic review included language other than English and case reports/case series reporting fewer than 10 patients. Evidence levels in the literature review were graded as previously described [30]. Based on our previous studies with receiver operator curves showing that a 5\% Ki-67 cutoff level provided the best fit for overall survival in a cohort that included patients with pulmonary typical and atypical carcinoids [2, 26], a Ki-67 cut-off value of 5\% was selected to stratify pulmonary carcinoid tumors in this study. Pulmonary atypical carcinoids were not stratified by this Ki-67 cut-off level for reasons explained in the Results. After Institutional Review Board approval, 256 consecutive cases diagnosed as pulmonary typical carcinoids and atypical carcinoids using World Health Organization criteria and with available $\mathrm{Ki}-67 \%$ results were retrieved from the archives of the Department of Pathology and Laboratory Medicine of Cedars-Sinai Medical Center. Ki-67\% was quantitated using image analysis, as previously described [26]. The cases were divided into 3 groups: A (pulmonary typical carcinoids with $\mathrm{Ki}-67 \%<5 \%$ ), B (pulmonary typical carcinoids with Ki-67\% $25 \%$ ) (Fig. 1a, b) and C (pulmonary atypical carcinoids). Pulmonary atypical carcinoids were not stratified by $\mathrm{Ki}-67 \%$ as there were only six cases with $\mathrm{Ki}-67 \%<5 \%$ and the group was quite heterogenous, as shown below. The age, sex, pathologic stage and follow-up information for patients was obtained from surgical pathology reports and our Medical Center's Tumor Registry. Overall survival, progression-free survival, recurrence proportions and time to recurrence were compared, by group, using Kaplan-Meier methodology with the log-rank test, chi-square statistics and analysis of variance, respectively.

\section{Results}

Thirty-three $(17.5 \%)$ of the oncologists responded to the survey; their answers are shown in Table 3 . All $33(100 \%)$ responders considered the information provided by the $\mathrm{Ki}$ 67 proliferative index important for treating patients with pulmonary carcinoid tumors and $81.8 \%$ of the responders indicated that they found it useful for informing patients about their prognosis. More than $90 \%$ of responders indicated that they would use a Ki-67 cut-off value of $>10 \%$ to suggest a more guarded prognosis and/or initiate therapy after surgical resection. Interestingly, to our knowledge, a $10 \% \mathrm{Ki}-67$ cut-off value has not been reported in the pathology literature as significant to stratify the prognosis of patients with pulmonary typical and atypical carcinoids or both tumors from high-grade neuroendocrine carcinomas. Confirming our hypothesis that oncologists at other institutions also experience difficulties with the current terminology, $63.6 \%$ of responders opined that the variable terminology currently used by pathologists to diagnose neuroendocrine neoplasms arising in different organs affects their clinical practice. Not surprisingly, almost $88 \%$ of responders considered it important to identify the site of origin of a neuroendocrine neoplasm.

The systematic literature review identified 42 relevant papers using the search strategy: Ki-67 and carcinoid and lung neoplasms [2-4, 7, 22-28, 31-59]. Studies in the literature provided only level III or IV evidence, and no randomized clinical trials of patients with pulmonary carcinoid tumors stratified by $\mathrm{Ki}-67 \%$ index were identified in the review. Table 4 shows our current data and the 11 studies from the review that provided the best available evidence to answer our questions [22, 26-28, 31, 32, 35, 36, 59-61]. As shown in the table, most studies used the hotspot method and manual counting to measure $\mathrm{Ki}-67 \%$ and proposed $\mathrm{Ki}-67$ cut-off values ranging from $1 \%$ to $7 \%$, although a cut-off of $4 \%$ or $5 \%$ appeared to provide significant survival differences in several studies. These cutoff values were estimated to distinguish pulmonary typical carcinoid tumors from pulmonary atypical carcinoid tumors in some studies and/or to provide significant prognostic information for cohorts that included both of these well-differentiated neuroendocrine neoplasms in other studies. We were not able to clearly classify the published data by diagnosis, Ki-67\% cut-off and prognosis and compare the data with metaanalysis. The study by Rindi et al. [35] provided the information that most closely answered our questions. This study proposed a 3-grade system to stratify the prognosis of patients with pulmonary neuroendocrine neoplasms, using $<4 \% \mathrm{Ki}-67 \%$ to distinguish grade 1 from grade 2 tumors. The study also utilized receiver operator curves to estimate the mitotic activity and percent of tumor necrosis that would correlate with a grade 
Fig. 1 a Photomicrograph of typical carcinoid tumor. The lesion shows minimal cytologic atypia, no necrosis and fewer than 2 mitoses/10 HPF. b The tumor shows a $\mathrm{Ki}-67 \%$ index of $9 \%$, higher than expected for a typical carcinoid
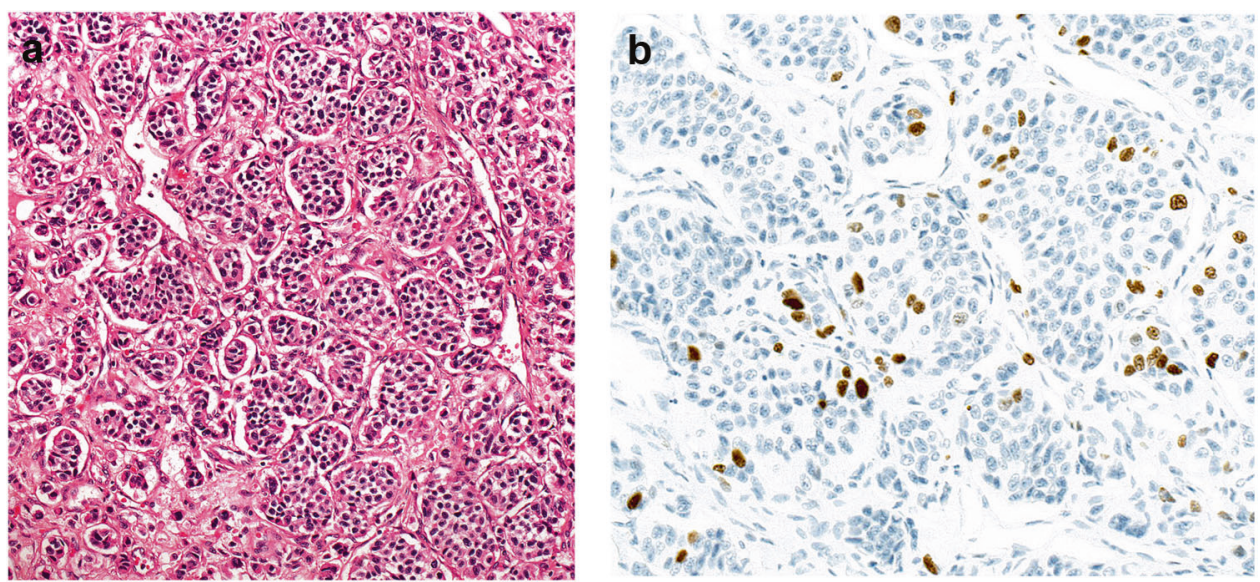

Table 3 Responses to the survey shown in Table $1(n=33)$

\begin{tabular}{lc}
\hline Questions & Yes \\
\hline $\begin{array}{l}\text { Is Ki-67 proliferative index useful } \\
\text { for therapy? }\end{array}$ & $100 \%$ \\
Is Ki-67 proliferative index useful & $81.8 \%$ \\
for prognosis? & \\
What Ki-67 cut-off is a "poor prognostic feature"? & $3.0 \%$ \\
$\quad 5 \%$ & $6.1 \%$ \\
$\quad 10 \%$ & $90.9 \%$ \\
$\quad>10 \%$ & $63.6 \%$ \\
$\begin{array}{l}\text { Does variability in NEN } \\
\text { terminology affect practice? }\end{array}$ \\
$\begin{array}{l}\text { Is it important to determine low- } \\
\text { grade NEN site of origin in patients } \\
\text { with metastatic lesions }\end{array}$
\end{tabular}

1-3 grading system but did not explain how to integrate these data with current World Health Organization diagnostic criteria for pulmonary carcinoid tumors in daily pathology practice.

A total of 256 cases, including 225 consecutive pulmonary typical carcinoids and 31 pulmonary atypical carcinoids, were available in our departmental files. Typical carcinoids included 187 group A cases (pulmonary typical carcinoids with $\mathrm{Ki}-67 \%<5 \%$ ) and 38 group B cases (pulmonary typical carcinoids with $\mathrm{Ki}-67 \% \geq 5 \%$ ). The pulmonary typical carcinoid cases included 221 primary tumors and 4 metastases (2 liver, 1 pancreas, 1 distant lymph node). The pulmonary typical carcinoids ranged in size from 0.4 to $7.0 \mathrm{~cm}$ (median $2.0 \mathrm{~cm}$ ). Staged by current American Joint Commission on Cancer criteria [62], they included 123 pT1a, 44 pT1b, 38 pT2, 6 pT2b and 14 pTX lesions [[101 pT1a N0; 3 pT1aN1; 2 pT1aN2; 14 pT1aNx; 2 pT1a(m)N0; 1 pT1aNxM1] [35 pT1bN0; 1 pT1bN1; 4 pT1bN2; 2 pT1bNx; 2 pT1bN0M1] [33 pT2aN0; 1
pT2aN1; 2 pT2aN2; 1 pT2aN1M1; 1 pT2a(m)N0] [3 pT2bN0; 1 pT2bN1; 1 pT2bN2M1; 1 pT2bN1] [1 pTXN0; 10 pTXNx; 1 pTXN3M1; 2 pTXNxM1]. The pulmonary typical carcinoid patients included 142 females and 83 males with median age of 59 years (8-89 years) at diagnosis. There was no significant difference in sex ratio, median age at diagnosis or median size of tumor between the two pulmonary typical carcinoid groups. Table 5 shows the findings in group B patients.

The pulmonary atypical carcinoid cases included 20 primary tumors and 11 metastases (4 distant lymph node, 3 liver and 4 other sites). The pulmonary atypical carcinoid patients included 23 females and 8 men with a median age of 67.5 years (41-88 years), and had a median age of 67.5 years (41-88 years). Staging information in the pulmonary atypical carcinoid group was variable and included 3 pT1aN0; 1 pT1aN2; 2 pT1aNx; 1 pT1bN0; 1 pT1bN2; 1 pTN2M1; 1 pTNxM1; 3 pT2aN1; 2 pT2aN2; 1 pT2aNx; 1 pT3N2; 1 pT3Nx; 1 pT3NxM1; 1 pT4N2M1; 1 pT4(m) N2M1; 1 pTXNOM1; 2 pTXN2; 1 pTXN1; and 6 pTXNxM1. The pulmonary atypical carcinoid group was not considered suitable to evaluate for recurrence proportions and time to recurrence as $30 \%$ of cases were already metastatic at diagnosis.

The Kaplan-Meier plot (Fig. 2) shows that, despite the longer follow-up available for group A than group B patients, with median follow-up of 96.5 months and 63.0 months, respectively, overall survivals were significantly worse in group $\mathrm{B}$ and $\mathrm{C}$ patients $(p=0.0001$, chi-squared $=21.56, \quad \mathrm{DF}=2)$. Figure 3 shows that progression-free survival was also significantly longer for group A than group B patients $(p<0.007$, chi-square 7.29, $\mathrm{DF}=1)$. Group $\mathrm{B}$ patients also experienced higher percentage of tumor recurrences $(12.5 \%$ vs $4.3 \%)$ and shorter mean times to recurrence $(38.0 \pm 18.4$ vs $64.6 \pm$ 47.6 months) than group A patients. However, these differences were not statistically significant $(p<0.12$, chisquared $=2.32$, and $p<0.3 \mathrm{~F}$ ratio $=1.12$, respectively). 


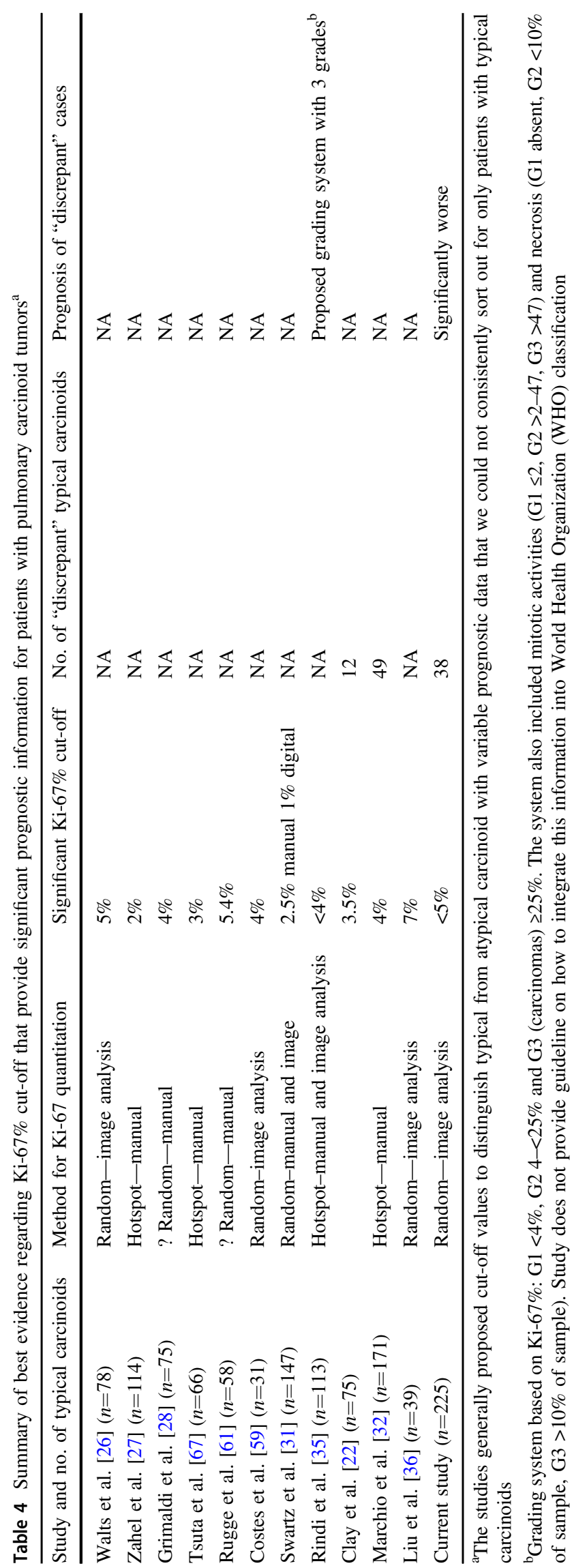

\section{Discussion}

Best evidence from the literature and our own experience suggests that a $\mathrm{Ki}-67 \%$ cut-off of $5 \%$, similar to the $4 \%$ cutoff suggested by Rindi et al. [35], could be used to stratify patients with typical carcinoid tumors of the lung into two subgroups, grade 1 and grade 2 well-differentiated neuroendocrine tumors, with significantly different overall survival, progression-free survival and perhaps different times to recurrence and proportions of local recurrence. Patients with pulmonary atypical tumors in the literature and in our cohort have significantly worse overall survival than those with pulmonary typical carcinoids and could be graded as grade 3 well-differentiated neuroendocrine tumors. The terminology grade 3 well-differentiated neuroendocrine tumors should not be used for the designation of pulmonary high-grade neuroendocrine carcinomas. The presence of a small number of pulmonary atypical carcinoid tumors with $\mathrm{Ki}-67 \%<5 \%$ in our cohort raises the question of whether these lesions should be graded as grade 1 or 2 well-differentiated neuroendocrine tumors, but there are no well documented patient series showing that pulmonary atypical carcinoid tumors with these $\mathrm{Ki}-67 \%$ values have similar prognosis to patients with pulmonary typical carcinoids and $<5 \% \mathrm{Ki}-67 \%$. As high-grade neuroendocrine carcinomas of the lung are well known to be highly aggressive neoplasms, these neoplasms could tentatively be graded as grade 4 neuroendocrine tumors or perhaps as grade 3 poorly differentiated neuroendocrine carcinomas, as used in the World Health Organization classification of gastroenteric and pancreatic neuroendocrine tumors. The use of the latter terminology could potentially create confusion between "grade 3 atypical carcinoids" and "grade 3 high-grade neuroendocrine carcinomas", but the World Health Organization schema suggest the term grade 3 welldifferentiated tumors for extrapulmonary atypical carcinoids and grade 3 poorly differentiated neuroendocrine carcinomas for high-grade neuroendocrine carcinomas (small-cell carcinoma and its variants and large-cell neuroendocrine carcinoma and its variants). Review of best evidence also suggests that it is probably futile to attempt to include $\mathrm{Ki}-67 \%$ as an additional diagnostic criterion in the World Health Organization histopathologic classification of pulmonary well-differentiated neuroendocrine tumors, as there is considerable overlap in $\mathrm{Ki}-67 \%$ values between typical carcinoids and atypical carcinoids and no investigator has been able, in spite of multiple attempts, to identify an unequivocal cut-off that would clearly distinguish both neoplasms. Additional prospective studies are needed to evaluate these questions more accurately.

The proposed grading system for patients with pulmonary well-differentiated neuroendocrine tumors, based on the combination of a 5\% Ki-67 cut-off and the World Health 
Table 5 Clinical and pathological information from group B patients with $\mathrm{Ki}-67 \% \geq$ $5 \%$ (proposed G2 typical carcinoids of lung origin)

\begin{tabular}{|c|c|c|c|c|c|c|c|}
\hline Case & Age & Sex & pTNM & $\mathrm{Ki}-67 \%$ & $\begin{array}{l}\text { Time to recurrence } \\
\text { (months) }\end{array}$ & $\begin{array}{l}\text { Overall survival } \\
\text { (months) }\end{array}$ & $\begin{array}{l}\text { Status at } \\
\text { follow-up }\end{array}$ \\
\hline 1 & 75 & $\mathrm{~F}$ & T1aNx & $9 \%$ & No recurrence & 163 & Dead \\
\hline 2 & 67 & M & T1N0 & $5 \%$ & No recurrence & 94 & Dead \\
\hline 3 & 56 & M & TXNO & $13 \%$ & Local+liver & 63 & Dead \\
\hline 4 & 39 & $\mathrm{~F}$ & T1aN2 & $18 \%$ & No recurrence & 130 & Alive \\
\hline 5 & 53 & $\mathrm{~F}$ & T1aN1 & $16 \%$ & Regional & 83 & Dead \\
\hline 6 & 64 & M & T1aN0 & $5 \%$ & No recurrence & 4.5 & Dead \\
\hline 7 & 72 & $\mathrm{~F}$ & T1(m)N0 & $5 \%$ & No recurrence & 128 & Alive \\
\hline 8 & 50 & $\mathrm{~F}$ & T2aN0 & $5 \%$ & No recurrence & 109 & Alive \\
\hline 9 & 67 & M & T1aN2 & $10 \%$ & No recurrence & 117 & Alive \\
\hline 10 & 71 & M & T1bN0 & $5 \%$ & No recurrence & 117 & Alive \\
\hline 11 & 69 & $\mathrm{~F}$ & T1aN0 & $7 \%$ & No recurrence & 108 & Dead \\
\hline 12 & 57 & $\mathrm{~F}$ & TxNxM1 & $9 \%$ & No recurrence & 42 & Dead \\
\hline 13 & 28 & $\mathrm{~F}$ & T1bN0 & $10 \%$ & No recurrence & 60 & Alive \\
\hline 14 & 81 & $\mathrm{~F}$ & T1aN0 & $5 \%$ & No recurrence & 90 & Alive \\
\hline 15 & 50 & $\mathrm{~F}$ & T1aN1 & $7 \%$ & No recurrence & 21 & Dead \\
\hline 16 & 45 & $\mathrm{~F}$ & T1aN0 & $23 \%$ & No recurrence & 74 & Alive \\
\hline 17 & 55 & M & TXNx & $22 \%$ & No recurrence & 86 & Alive \\
\hline 18 & 52 & $\mathrm{~F}$ & TXNx & $14 \%$ & No recurrence & 60 & Alive \\
\hline 19 & 59 & M & T2aNo & $7 \%$ & Liver & 87 & Alive \\
\hline 20 & 73 & M & T1aN0 & $5 \%$ & No recurrence & 69 & Alive \\
\hline 21 & 54 & $\mathrm{~F}$ & $\mathrm{TXNx}$ & $11 \%$ & No recurrence & 62 & Alive \\
\hline 22 & 22 & $\mathrm{~F}$ & T2aN0 & $5 \%$ & Local & 24 & Alive \\
\hline 23 & 20 & $\mathrm{~F}$ & T1aN0 & $6 \%$ & No recurrence & 45 & Alive \\
\hline 24 & 66 & M & T1aN0 & $5 \%$ & No recurrence & 44 & Alive \\
\hline 25 & 31 & M & T1aN0 & $5 \%$ & No recurrence & 2 & Alive \\
\hline 26 & 47 & $\mathrm{~F}$ & T1bN0M1 & $9 \%$ & No recurrence & 42 & Alive \\
\hline 27 & 61 & M & T2aN0 & $8 \%$ & No recurrence & 38 & Alive \\
\hline 28 & 75 & M & T1aNo & $5 \%$ & No recurrence & 1 & Alive \\
\hline 29 & 64 & $\mathrm{M}$ & TxNxM1 & $7 \%$ & No recurrence & 13 & Alive \\
\hline 30 & 74 & $\mathrm{~F}$ & T2aNO & $8 \%$ & No recurrence & 60 & Alive \\
\hline 31 & 59 & $\mathrm{M}$ & $\mathrm{T} 2 \mathrm{bNx}$ & $7 \%$ & No recurrence & 21 & Alive \\
\hline 32 & 61 & $\mathrm{M}$ & T2aNo & $5 \%$ & No recurrence & 20 & Alive \\
\hline 33 & 24 & $\mathrm{M}$ & T1aN0 & $5 \%$ & No recurrence & 5 & Alive \\
\hline 34 & 29 & $\mathrm{M}$ & T1aN0 & $5 \%$ & No recurrence & 160 & Alive \\
\hline 35 & 73 & $\mathrm{~F}$ & T1bN0 & $10 \%$ & No recurrence & 70 & Dead \\
\hline 36 & 84 & $\mathrm{~F}$ & T1aN1 & $6 \%$ & No recurrence & 98 & Dead \\
\hline 37 & 77 & $\mathrm{~F}$ & T1aNx & $5 \%$ & No recurrence & 119 & Alive \\
\hline 38 & 82 & $\mathrm{~F}$ & T1aN0 & $6 \%$ & No recurrence & 111 & Alive \\
\hline
\end{tabular}

Organization classification of carcinoid tumors, could be used as a risk stratification tool for the prognostication and treatment of these patients. For example, based on their favorable prognosis, patients with grade 1 welldifferentiated neuroendocrine tumors should undergo a limited surveillance plan and should not receive any adjuvant therapy after surgical resection. Patients and their oncologists would probably feel comfortable with such a watch and wait approach. In contrast, adjuvant chemotherapy and/or a more frequent surveillance plan would probably be recommended to patients with higher grade well-differentiated neuroendocrine tumors.

The proposed grading system for patients with pulmonary neuroendocrine neoplasms is based on best level III and IV evidence collected from retrospective studies and our own experience and needs to be validated with prospective studies that include considerably larger numbers of patients. Pulmonary carcinoid tumors are relatively 


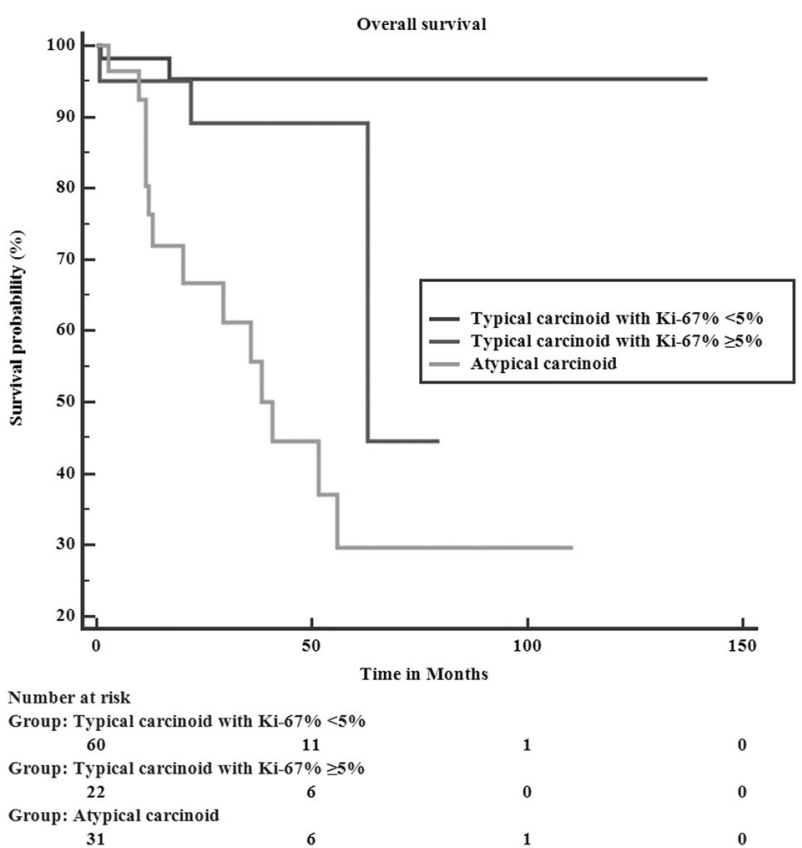

Fig. 2 Kaplan-Meier curve showing overall survival of patients with typical and atypical carcinoid tumors

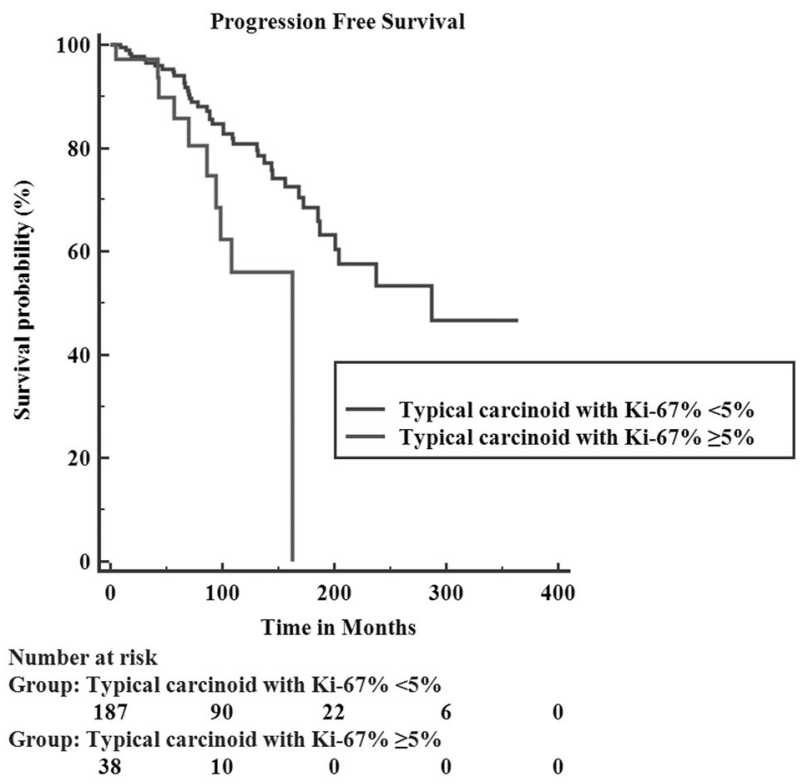

Fig. 3 Kaplan-Meier curve showing progression-free survival of patients with typical carcinoid tumors

infrequent neoplasms with a generally indolent natural history and our prognostic estimates and those in the literature are based on the analysis of relatively few recurrence events. Hence, such studies will probably require the development of an international data repository where many cases diagnosed at multiple institutions could be evaluated, similarly to the recent experience collected by the International Thymic Neoplasms Interest Group for thymomas [62].
In order to optimize therapy for patients in the era of precision medicine, the World Health Organization classification of pulmonary neuroendocrine neoplasms and the proposed grading system will probably need to be supplemented with the molecular characteristics of these neoplasms in the future [63]. As recently reviewed by Rossi et al. [64], neuroendocrine tumors of the lung have variable molecular alterations. For example, pulmonary carcinoid tumors often exhibit MEN1 mutations while high-grade neuroendocrine carcinomas show higher rates of chromosomal aberrations in $3 p, 17 p$ and other loci. High-grade neuroendocrine carcinomas also exhibit inactivation of the TP53 and RB1 genes, and up-regulation of c-Kit, plateletderived growth factor receptor (PDGFR) and epidermal growth factor receptor (EGFR) and other tyrosine kinase receptors, but it is not yet known how to use this information to guide therapy [64]. More promising has been the approval in 2016 of the mammalian target of rapamycin (mTOR) inhibitor everolimus for the treatment of progressive pulmonary well-differentiated neuroendocrine tumors based on the results of the RADIANT-4 trial [65]. Gagliano et al. [66] have shown that levels of mTOR, p7056K, AKT and extracellular signal-regulated kinase 1/2 (ERK1/2) appear to correlate with response to this therapy [65]. These efforts will hopefully result in a more nuanced and uniform classification system for pulmonary neuroendocrine neoplasms that will allow clinicians to select specific therapies with greater precision, to more accurately assess the relative effectiveness of various approaches in clinical trials, and to better align the treatment of pulmonary carcinoid tumors within the broader context of neuroendocrine neoplasms.

Acknowledgements The authors thank the leadership of the North American Neuroendocrine Tumor Society (NANETS) for authorizing the distribution of our survey, their staff member Alissa Petsche who coordinated the survey and our colleague Dr. Deepti Dhal who helped interpret the diagnostic criteria for gastroenteric-pancreatic neuroendocrine neoplasms.

\section{Compliance with ethical standards}

Conflict of interest The authors declare that they have no conflict of interest.

\section{References}

1. Creutzfeldt W. Historical background and natural history of carcinoids. Digestion. 1994;55(Suppl 3):3-10.

2. Marchevsky AM, Walts AE, Wick MR. Evidence-based pathology in its second decade: toward probabilistic cognitive computing. Hum Pathol. 2017;61:1-8.

3. Pelosi G, Pattini L, Morana G, et al. Grading lung neuroendocrine tumors: controversies in search of a solution. Histol Histopathol. 2017;32:223-41. 
4. Pelosi G, Sonzogni A, Harari S, et al. Classification of pulmonary neuroendocrine tumors: new insights. Transl Lung Cancer Res. 2017;6:513-29.

5. Chaabane A, M'Sakni I, Laabidi B, et al. Digestive neuroendocrine tumors: reclassifying of 26 cases according to 2010 who classification. Tunis Med. 2016;94:580-6.

6. Kouba E, Cheng L. Neuroendocrine tumors of the urinary bladder according to the 2016 World Health Organization Classification: molecular and clinical characteristics. Endocr Pathol. 2016;27: 188-99.

7. Ricci C, Casadei R, Taffurelli G, et al. Validation of the 2010 WHO classification and a new prognostic proposal: a single centre retrospective study of well-differentiated pancreatic neuroendocrine tumours. Pancreatology. 2016;16:403-10.

8. Priemer DS, Montironi R, Wang L, et al. Neuroendocrine tumors of the prostate: emerging insights from molecular data and updates to the 2016 World Health Organization classification. Endocr Pathol. 2016;27:123-35.

9. Travis WD. Pathology and diagnosis of neuroendocrine tumors: lung neuroendocrine. Thorac Surg Clin. 2014;24:257-66.

10. Travis WD, Linnoila RI, Tsokos MG, et al. Neuroendocrine tumors of the lung with proposed criteria for large-cell neuroendocrine carcinoma. An ultrastructural, immunohistochemical, and flow cytometric study of 35 cases. Am J Surg Pathol. 1991;15:529-53.

11. Travis WD. Advances in neuroendocrine lung tumors. Ann Oncol. 2010;21(Suppl 7):vii65-71.

12. Travis WD. Lung tumours with neuroendocrine differentiation. Eur J Cancer. 2009;45(Suppl 1):251-66.

13. Travis WD, Gal AA, Colby TV, et al. Reproducibility of neuroendocrine lung tumor classification. Hum Pathol. 1998;29:272-9.

14. Travis WD, Rush W, Flieder DB, et al. Survival analysis of 200 pulmonary neuroendocrine tumors with clarification of criteria for atypical carcinoid and its separation from typical carcinoid. Am J Surg Pathol. 1998;22:934-44.

15. Marchevsky AM, Wick MR. Introduction--neuroendocrine neoplasms of the lung. Semin Diagn Pathol. 2015;32:419.

16. Marchevsky AM. Neuroendocrine tumors of the lung. Pathology (Phila). 1996;4:103-23.

17. Hendifar AE, Marchevsky AM, Tuli R. Neuroendocrine tumors of the lung: current challenges and advances in the diagnosis and management of well-differentiated disease. J Thorac Oncol. 2017;12:425-36.

18. Kim JY, Hong S-M. Recent updates on neuroendocrine tumors from the gastrointestinal and pancreatobiliary tracts. Arch Pathol Lab Med. 2016;140:437-48.

19. Tang LH, Basturk O, Sue JJ, Klimstra DS. A practical approach to the classification of WHO Grade 3 (G3) well-differentiated neuroendocrine tumor (WD-NET) and poorly differentiated neuroendocrine carcinoma (PD-NEC) of the pancreas. Am J Surg Pathol. 2016;40:1192-202.

20. Lloyd RV, Osamura RY, Kloppel G, Rosai J. Neoplasms of the neuroendocrine pancreas. In: Lloyd RV, OR, Kloppel G, Rosai J, editors. Classification of Tumours of Endocrine Organs. Lyon: IARC Press; 2017. p. 209-39.

21. Goldman A, The malignant nature of bronchial adenoma. J Thorac Surg. 1949;18:137-48.155-63, Disc.

22. Clay V, Papaxoinis G, Sanderson B, et al. Evaluation of diagnostic and prognostic significance of Ki-67 index in pulmonary carcinoid tumours. Clin Transl Oncol. 2017;19:579-86.

23. Fabbri A, Cossa M, Sonzogni A, et al. Ki-67 labeling index of neuroendocrine tumors of the lung has a high level of correspondence between biopsy samples and surgical specimens when strict counting guidelines are applied. Virchows Arch. 2017;470: $153-64$
24. Joseph MG, Shibani A, Panjwani N, Arab A, Shepherd J, Stitt LW, Inculet R. Usefulness of Ki-67, mitoses, and tumor size for predicting metastasis in carcinoid tumors of the lung: a study of 48 cases at a tertiary care centre in Canada. Lung Cancer Int. 2015;2015:545601.

25. Warth A,Fink L,Fisseler-Eckhoff A,Jonigk D,Keller M,Ott G, Rieker RJ,Sinn P,Soder S,Soltermann A,Willenbrock K,Weichert W,Pulmonary Pathology Working Group of the German Society of Pathology. Interobserver agreement of proliferation index (Ki67) outperforms mitotic count in pulmonary carcinoids. Virchows Arch. 2013;462:507-13.

26. Walts AE, Ines D, Marchevsky AM. Limited role of Ki-67 proliferative index in predicting overall short-term survival in patients with typical and atypical pulmonary carcinoid tumor. Mod Pathol. 2012;25:1258-64.

27. Zahel T, Krysa S, Herpel E, Stenzinger A, Goeppert B, Schirmacher P, Hoffmann H, Schnabel PA, Warth A. Phenotyping of pulmonary carcinoids and a Ki-67-based grading approach. Virchows Arch. 2012;460:299-308.

28. Grimaldi F, Muser D, Beltrami CA, Machin P, Morelli A, Pizzolitto S, Talmassons G, Marciello F, Colao AA, Monaco R, Monaco G, Faggiano A. Partitioning of bronchopulmonary carcinoids in two different prognostic categories by ki-67 score. Front Endocrinol (Lausanne). 2011;2:20.

29. Marchevsky AM, Wick MR. Evidence-based pathology: systematic literature reviews as the basis for guidelines and best practices. Arch Pathol Lab Med. 2015;139:394-9.

30. Marchevsky AM, Wick MR. Evidence levels for publications in pathology and laboratory medicine. Am J Clin Pathol. 2010;133:366-7.

31. Swarts DR, Rudelius M, Claessen SM, Cleutjens JP, Seidl S, Volante M, Ramaekers FC, Speel EJ. Limited additive value of the Ki-67 proliferative index on patient survival in World Health Organization-classified pulmonary carcinoids. Histopathology. 2017;70:412-22.

32. Marchio C, Gatti G, Massa F, Bertero L, Filosso P, Pelosi G, Cassoni P, Volante M, Papotti M. Distinctive pathological and clinical features of lung carcinoids with high proliferation index. Virchows Arch. 2017;471:713-20.

33. Pelosi G, Fabbri A, Cossa M, Sonzogni A, Valeri B, Righi L, Papotti M. What clinicians are asking pathologists when dealing with lung neuroendocrine neoplasms? Semin Diagn Pathol. 2015;32:469-79.

34. Pelosi G, Rindi G, Travis WD, Papotti M. Ki-67 antigen in lung neuroendocrine tumors: unraveling a role in clinical practice. $\mathrm{J}$ Thorac Oncol. 2014;9:273-84.

35. Rindi G, Klersy C, Inzani F, et al. Grading the neuroendocrine tumors of the lung: an evidence-based proposal. Endocr Relat Cancer. 2014;21:1-16.

36. Liu SZ, Staats PN, Goicochea L, Alexiev BA, Shah N, Dixon R, Burke AP. Automated quantification of Ki-67 proliferative index of excised neuroendocrine tumors of the lung. Diagn Pathol. 2014;9:174.

37. Lantuejoul S. [2014 classification of lung carcinomas: latest entities and clinical implications. Case 5: Lymph node metastasis of an atypical carcinoid]. Ann Pathol. 2013;33:322-4.

38. Zhu L, Shen-Tu Y, Zhang J, Fan X. [Pathological characteristic and clinical management of pulmonary carcinoid]. Zhongguo Fei Ai Za Zhi. 2013;16:246-51.

39. Zheng G, Ettinger DS, Maleki Z. Utility of the quantitative Ki-67 proliferation index and CD56 together in the cytologic diagnosis of small cell lung carcinoma and other lung neuroendocrine tumors. Acta Cytol. 2013;57:281-90.

40. Demirci I, Herold S, Kopp A, Flasshove M, Klosterhalfen B, Janssen H. Overdiagnosis of a typical carcinoid tumor as an 
adenocarcinoma of the lung: a case report and review of the literature. World J Surg Oncol. 2012;10:19.

41. Stoll LM, Johnson MW, Burroughs F, Li QK. Cytologic diagnosis and differential diagnosis of lung carcinoid tumors a retrospective study of 63 cases with histologic correlation. Cancer Cytopathol. 2010;118:457-67.

42. Liao H, Rao H, Zhang X, Lin Y, Jie M, Fu J, Long H, Rong T, Lin P. [Retrospective study of clinicopathological characteristics in bronchopulmonary carcinoid]. Zhongguo Fei Ai Za Zhi. 2010; 13:591-7.

43. Skov BG, Holm B, Erreboe A, Skov T, Mellemgaard A. ERCC1 and Ki67 in small cell lung carcinoma and other neuroendocrine tumors of the lung: distribution and impact on survival. J Thorac Oncol. 2010;5:453-9.

44. Drozdov I, Kidd M, Nadler B, Camp RL, Mane SM, Hauso O, Gustafsson BI, Modlin IM. Predicting neuroendocrine tumor (carcinoid) neoplasia using gene expression profiling and supervised machine learning. Cancer. 2009;115:1638-50.

45. Pelosi G, Rodriguez J, Viale G, Rosai J. Typical and atypical pulmonary carcinoid tumor overdiagnosed as small-cell carcinoma on biopsy specimens: a major pitfall in the management of lung cancer patients. Am J Surg Pathol. 2005;29:179-87.

46. Aslan DL, Gulbahce HE, Pambuccian SE, Manivel JC, Jessurun J. Ki-67 immunoreactivity in the differential diagnosis of pulmonary neuroendocrine neoplasms in specimens with extensive crush artifact. Am J Clin Pathol. 2005;123:874-8.

47. Igarashi T, Jiang SX, Kameya T, Asamura H, Sato Y, Nagai K, Okayasu I. Divergent cyclin B1 expression and Rb/p16/cyclin D1 pathway aberrations among pulmonary neuroendocrine tumors. Mod Pathol. 2004;17:1259-67.

48. Amarapurkar AD, Davies A, Ramage JK, Stangou AJ, Wight DG, Portmann BC. Proliferation of antigen MIB-1 in metastatic carcinoid tumours removed at liver transplantation: relevance to prognosis. Eur J Gastroenterol Hepatol. 2003;15:139-43.

49. Lin O, Olgac S, Green I, Zakowski MF, Klimstra DS. Immunohistochemical staining of cytologic smears with MIB-1 helps distinguish low-grade from high-grade neuroendocrine neoplasms. Am J Clin Pathol. 2003;120:209-16.

50. Pelosi G, Pasini F, Sonzogni A, et al. Prognostic implications of neuroendocrine differentiation and hormone production in patients with stage I nonsmall cell lung carcinoma. Cancer. 2003;97:2487-97.

51. Pelosi G, Pasini F, Fraggetta F, Pastorino U, Iannucci A, Maisonneuve P, Arrigoni G, De Manzoni G, Bresaola E, Viale G. Independent value of fascin immunoreactivity for predicting lymph node metastases in typical and atypical pulmonary carcinoids. Lung Cancer. 2003;42:203-13.

52. Resl M, Simek J, Bukac J, Rothrockel P, Siller J. DNA topoisomerase II-alpha in pulmonary carcinoid tumor. Pathol Res Pract. 2001;197:169-73.

53. Arbiser ZK, Arbiser JL, Cohen C, Gal AA. Neuroendocrine lung tumors: grade correlates with proliferation but not angiogenesis. Mod Pathol. 2001;14:1195-9.
54. Helpap B, Kollermann J. Immunohistochemical analysis of the proliferative activity of neuroendocrine tumors from various organs. Are there indications for a neuroendocrine tumorcarcinoma sequence? Virchows Arch. 2001;438:86-91.

55. Granberg D, Wilander E, Oberg K, Skogseid B. Prognostic markers in patients with typical bronchial carcinoid tumors. J Clin Endocrinol Metab. 2000;85:3425-30.

56. Laitineuroendocrine neoplasm KL, Soini Y, Mattila J, Paakko P. Atypical bronchopulmonary carcinoids show a tendency toward increased apoptotic and proliferative activity. Cancer. 2000;88: $1590-8$.

57. Zirbes TK, Lorenzen J, Baldus SE, et al. Apoptosis and expression of bcl-2 protein are inverse factors influencing tumour cell turnover in primary carcinoid tumours of the lung. Histopathology. 1998;33:123-8.

58. Al-Khafaji B, Noffsinger AE, Miller MA, et al. Immunohistologic analysis of gastrointestinal and pulmonary carcinoid tumor. Hum Pathol. 1998;29:992-9.

59. Costes V, Marty-Ane C, Picot MC, et al. Typical and atypical bronchopulmonary carcinoid tumor: a clinicopathologic and Ki67-labeling study. Hum Pathol. 1995;26:740-5.

60. Tsuta K, Kalhor N, Raso MG, et al. Oncocytic neuroendocrine tumors of the lung: histopathologic spectrum and immunohistochemical analysis of 15 cases. Hum Pathol. 2011;42:578-85.

61. Rugge M, Fassan M, Clemente R, et al. Bronchopulmonary carcinoid: phenotype and long-term outcome in a single-institution series of Italian patients. Clin Cancer Res. 2008;14: 149-54.

62. Shepherd A, Riely G, Detterbeck F, et al. Thymic carcinoma management patterns among International Thymic Malignancy Interest Group (ITMIG) physicians with consensus from the Thymic Carcinoma Working Group. J Thorac Oncol. 2017;12: 745-51.

63. Wolin EM. Challenges in the diagnosis and management of welldifferentiated neuroendocrine tumors of the lung (typical and atypical carcinoid): current status and future considerations. Oncologist. 2015;20:1123-31.

64. Rossi G, Bertero L, Marchio C, Papotti M. Molecular alterations of neuroendocrine tumours of the lung. Histopathology. 2018;72: 142-52.

65. Yao JC, Fazio N, Singh S, et al. Everolimus for the treatment of advanced, non-functional neuroendocrine tumours of the lung or gastrointestinal tract (RADIANT-4): a randomised, placebo-controlled, phase 3 study. Lancet. 2016;387:968-77.

66. Gagliano T, Bellio M, Gentilin E, et al. mTOR, p70S6K, AKT, and ERK1/2 levels predict sensitivity to mTOR and PI3K/mTOR inhibitors in human bronchial carcinoids. Endocr Relat Cancer. 2013;20:463-75.

67. Tsuta K, Liu DC, Kalhor N, Wistuba II, Moran CA. Using the mitosis-specific marker anti-phosphohistone $\mathrm{H} 3$ to assess mitosis in pulmonary neuroendocrine carcinomas. Am J Clin Pathol. 2011;136:252-9. 